\title{
Psychiatric and social aspects of brittle asthma
}

\author{
G M F Garden, J G Ayres
}

\begin{abstract}
Background-Many studies have shown that emotional factors play a part in asthma, but few have compared patients with differing severities of asthma. It was our impression that patients with "brittle" asthma (BA; more than 40\% diurnal variation in peak flow on 15 or more days a month over a period of at least six months, and persistent symptoms despite multiple drug treatment) had greater psychosocial morbidity than asthmatic patients with less variable asthma.
\end{abstract}

Methods-Twenty patients with BA and a control group of less severe asthmatic subjects matched for age, sex, and duration of illness were asked to complete the General Health Questionnaire (GHQ), a screening test for psychiatric disorders, the Eysenck Personality Inventory which measures extraversion and neuroticism, and to participate in a life events interview and a structured clinical interview (SCID) to diagnose psychiatric disorder. Results-The mean (SD) age was 45.6 (12.3) years for the BA group, and 45.7 (13.1) years for the control group. All patients were receiving inhaled steroids and regular $\beta_{2}$ agonists; nine patients with BA but no control patients were taking oral steroids, and 12 of the patients with $B A$ but no controls were receiving $\beta_{2}$ agonists by subcutaneous infusion or injection. Eight of the patients with BA scored more than 11 on the GHQ compared with five of the control group (NS). Significantly more subjects with BA (12/20) than controls $(5 / 20)$ had intercurrent or past psychiatric disorder, and 7/20 subjects with BA had a lifetime history of anxiety disorder compared with $3 / 20$ controls. Life events analysis showed no overall difference in the total number, but the patients with BA had significantly more life events related to asthma. There was no difference in personality profiles between the two groups.

Conclusions-The results suggest that patients with "brittle" asthma have greater psychiatric morbidity than those with less severe asthma, but that their personality profiles and overall life event experiences are similar.

(Thorax 1993;48:501-505)
There is now considerable evidence to suggest that emotional factors play a part in asthma, but there is little agreement on the extent to which such factors occur. Although Rees $^{1}$ suggested that psychogenic factors were important in asthma, a later report on mild asthmatic patients in general practice failed to show a difference in incidence of mental illness compared with a group of non-asthmatic subjects from the same population. ${ }^{2}$

Advances in the treatment of asthma have had a disappointing impact upon morbidity and mortality. Furthermore, mortality appears to be associated with poor control, poor compliance, and an increased incidence of psychosocial morbidity, ${ }^{3}$ so elucidation of the nature of psychiatric and social factors in severe and poorly controlled asthma may be particularly important in the management of this condition. We have therefore conducted a case-control study of a group of asthmatic patients with marked diurnal variation in peak expiratory flow (PEF), despite considerable medication, which we have termed "brittle" asthma. Turner-Warwick first used this term in $1977,{ }^{4}$ but at that time defined it in qualitative rather than quantitative terms. The term was used subsequently by one of the authors (JA) in another study. ${ }^{5}$ Although "brittle" asthma is an arbitrary term, it has been used in this study to describe, in the most concise manner possible, a group of patients with a defined and persistent marked diurnal variation in PEF despite multiple drug treatment.

The aim of the study was to examine whether patients with "brittle" asthma have more psychiatric morbidity and adverse life events than do patients with less severe asthma.

\section{Methods}

\section{SUBJECTS}

Twenty two patients attending respiratory outpatient clinics, who had previously been designated as having brittle asthma, were asked to participate in the study. One patient had developed expressive dysphasia after a recent cerebrovascular accident which made her unsuitable, and another patient declined to participate since she was a member of staff. Twenty patients therefore agreed to participate. Brittle asthma (BA) was defined as more than $40 \%$ diurnal variation in $\mathrm{PEF}$ (maximum PEF - minimum $\mathrm{PEF} /$ maximum

Received 8 January 92 Returned to auth 
PEF $\times 100$ ) on 15 or more days a month for at least six months, and persistent symptoms despite multiple drug treatment. Multiple drug treatment consisted of more than 1000 $\mu \mathrm{g} /$ day inhaled steroids (mean $2390 \mu \mathrm{g} /$ day, range $1000-4000 \mu \mathrm{g} /$ day) and at least two other regular drugs for asthma including regular high dose inhaled bronchodilators $\left(\beta_{2}\right.$ agonists or anticholinergic agents nebulised or via inhaler), oral bronchodilators where tolerated $\left(\beta_{2}\right.$ agonists or xanthines), and either maintenance or recurrent courses of oral steroids. Twenty control patients, matched with the BA group for age, sex, and duration of symptoms of asthma, were randomly selected from the same respiratory outpatient clinics as the subjects with BA. All had shown more than $15 \%$ reversibility to inhaled $\beta_{2}$ agonists, or more than $20 \%$ diurnal variation in PEF in conjunction with a clinical history suggesting the diagnosis, or both. With the exception of one person, all subjects asked to be control patients agreed to participate in the study.

\section{QUESTIONNAIRES}

Each subject was asked to complete a questionnaire giving demographic details and information about their asthma, and two self administered questionnaires-the General Health Questionnaire (GHQ), ${ }^{6}$ and the Eysenck Personality Inventory (EPI). ${ }^{7}$ The GHQ consists of 60 items each with four possible responses, and takes approximately 10 minutes to complete. It was designed to detect psychiatric cases in the primary care or general medical outpatient setting, and has a high specificity $(94 \%)$ and sensitivity $(91 \%){ }^{6}$ A score of 11 is the threshold for a psychiatric case. ${ }^{8}$ The EPI is a development of the Maudsley Personality Inventory; it measures two major dimensions of personality - extroversion and neuroticism-and also contains a lie scale.

\section{INTERVIEWS}

Each subject was interviewed with the structured clinical interview (SCID) for the Diagnostic and Statistical Manual of Mental Disorders, 3rd edition (revised) (DSM-III-R). ${ }^{9}$ The DSM-III-R is a comprehensive diagnostic system which is widely used throughout the world. In addition, the Cambridge interview for recent life events ${ }^{10}$ was conducted with each patient. This is a semistructured interview containing 63 event specific variables in nine categories; work, education, finance, health, bereavement, migration, courtship and cohabitation, legal, family and social relationships. The events were graded in terms of the objective negative impact on the individual - that is, severe, marked, moderate, mild, and no negative impact. The interviewer was unaware of the GHQ and EPI scores when the SCID and life event interviews were conducted; she could not, however, be blind to which group the patient was from since detailed interview revealed the nature of the patient's asthma, and many of the patients with BA were wearing sub- cutaneous infusion pumps which were both audible and visible.

\section{ANALYSIS}

Since this study was a case-control study, the binomial test was used to compare paired proportions for results from the GHQ and the SCID. The power of the SCID to detect a $5 \%$ difference in the prevalence of psychiatric disorder between the two groups in this study was $83.5 \%$. The Shapiro Wilk test was used to determine whether parametric or nonparametric tests should be used for the remaining results. Paired $t$ tests were carried out on results which were normally distributed, namely the extroversion scale of the EPI, the SCID global function scores, and the results of the spirometry. The Wilcoxon rank sign test was used to compare the life event data and the other data from the EPI.

Approval was received from the ethics committee at East Birmingham Hospital.

\section{Results}

Demographic details of the two groups are given in table 1 , and treatment is recorded in table 2. Lung function tests performed at the time of the interviews showed that mean (SD) forced expiratory volume in one second $\%$ predicted $\left(\mathrm{FEV}_{1}\right)$ in the patients with $\mathrm{BA}$ $(70.9(18.5)$; range 23.5-91.6) was significantly lower than that of the control group

Table 1 Demographic details of subjects

\begin{tabular}{lcc}
\hline & $\begin{array}{l}\text { Brittle } \\
\text { asthma }\end{array}$ & $\begin{array}{l}\text { Control } \\
\text { group }\end{array}$ \\
\hline Age (y): & & \\
Mean (SD) & $45 \cdot 6(12 \cdot 3)$ & $45 \cdot 7(13 \cdot 1)$ \\
Range & $22-66$ & $23-69$ \\
Socioeconomic status & & \\
I & 0 & 1 \\
II & 5 & 6 \\
III & 10 & 7 \\
IV & 4 & 6 \\
V & 1 & 0 \\
Marital state: & 9 & 12 \\
Married & 5 & 4 \\
Divorced/separated & 5 & 3 \\
Single & 1 & 1 \\
Widowed & 13 & 9 \\
Atopy & & \\
Smoking history & 2 & 3 \\
Current & 6 & 7 \\
Past & 12 & 10 \\
$\quad$ Never & & $0 \cdot 2$ \\
Hospitalisations for asthma & $1 \cdot 7$ & \\
in last year (mean) & $1 \cdot 7$ \\
\hline
\end{tabular}

Table 2 Numbers of patients taking specific types of treatment for asthma

\begin{tabular}{lcc}
\hline & $\begin{array}{l}\text { Brittle } \\
\text { asthma }\end{array}$ & $\begin{array}{l}\text { Control } \\
\text { group }\end{array}$ \\
\hline Inhaled bronchodilators & 20 & 20 \\
Inhaled steroids & 20 & 20 \\
$\quad$ Mean dose $(\mu \mathrm{g} /$ day $)$ & 2390 & 1060 \\
Range & $1000-4000$ & $400-2400$ \\
Oral bronchodilators & 12 & 3 \\
Oral steroids & 9 & 0 \\
Subcutaneous $\beta_{2}$ agonist & 12 & 0 \\
Other prophylactic agents & 2 & 0 \\
\hline
\end{tabular}


( 85.0 (18.8); range 57-117.5), and the mean (SD) \% predicted forced vital capacity (FVC) was significantly lower in the patients with BA (85.9 (22.2); range 27.6-114.9) than in the control group $(102.6(15.4)$; range $54 \cdot 0-129.0)(p<0.02)$, although there was no significant difference between the two groups for $\mathrm{FEV}_{1} / \mathrm{FVC}$ ( 71.5 for the patients with $\mathrm{BA}$, 70.9 for controls). Results of the GHQ, EPI, SCID, and the life event schedule are summarised in table 3 . There was a significantly increased lifetime prevalence of psychiatric disorder in the patients with BA compared with the control group $(p<0.02)$. A breakdown of the individual disorders detected by the SCID is given in table 4. Six of the patients with BA, but only one of the control group, were found to have an intercurrent anxiety disorder (NS). Twelve of the patients with BA $(60 \%)$ were being treated with subcutaneous terbutaline, 10 via a continuous infusion pump, and two by intermittent injection. Of the 12 patients with $\mathrm{BA}$ who were receiving subcutaneous terbutaline, four had intercurrent anxiety disorders, compared with two of the eight patients who were not receiving this treatment (NS). Oral steroids were being taken by nine of the patients with BA $(45 \%)$, but by none of the control group. Two of the former were found to have an

Table 3 Results of GHQ, EPI, SCID, and life event schedule

\begin{tabular}{|c|c|c|}
\hline & $\begin{array}{l}\text { Brittle } \\
\text { asthma }\end{array}$ & $\begin{array}{l}\text { Control } \\
\text { group }\end{array}$ \\
\hline GHQ score >11 & 8 & 5 \\
\hline \multicolumn{3}{|l|}{ EPI, mean (SD): } \\
\hline Extroversion & $12.95(4.86)$ & $14.0(3.98)$ \\
\hline Neuroticism & $12.95(5 \cdot 22)$ & $12 \cdot 9(4.96)$ \\
\hline Lie scale & $2 \cdot 1(1 \cdot 29)$ & $1.95(1 \cdot 19)$ \\
\hline \multicolumn{3}{|l|}{ SCID: } \\
\hline Intercurrent illness & 8 & 2 \\
\hline Past psychiatric disorder & 7 & 3 \\
\hline \multicolumn{3}{|l|}{ Intercurrent and past } \\
\hline $\begin{array}{l}\text { psychiatric disorder } \\
\text { Global function }\end{array}$ & $\begin{array}{l}12^{\star} \\
72 \cdot 55\end{array}$ & $\begin{array}{c}5^{\star} \\
77 \cdot 25\end{array}$ \\
\hline \multicolumn{3}{|l|}{ Life events, mean (SD): } \\
\hline Total & $2 \cdot 5(1 \cdot 8)$ & $2 \cdot 2(1 \cdot 6)$ \\
\hline Asthma & $1.0(0.9)^{\star \star}$ & $0 \cdot 2(0.4)^{\star \star}$ \\
\hline
\end{tabular}

Table 4 Results of structured clinical interview (SCID)

\begin{tabular}{lll}
\hline & $\begin{array}{l}\text { Brittle } \\
\text { asthma }\end{array}$ & $\begin{array}{l}\text { Control } \\
\text { group }\end{array}$ \\
\hline Mood disorders & & \\
$\quad$ Past & 6 & 3 \\
$\quad$ Present & 3 & 0 \\
Psychotic disorders & 2 & 0 \\
$\quad$ Past & 0 & 0 \\
$\quad$ Present & & \\
Psychoactive substance disorders & 2 & 0 \\
$\quad$ Past & 1 & 0 \\
$\quad$ Present & & \\
Anxiety disorders & 1 & 2 \\
$\quad$ Past & 6 & 1 \\
$\quad$ Present & & \\
Somatoform disorders & 0 & 0 \\
$\quad$ Past & 0 & 0 \\
$\quad$ Present & & \\
$\quad$ Past & 0 & 0 \\
$\quad$ Present & 0 & 0 \\
Adjustment disorders & & \\
$\quad$ Past & 0 & 0 \\
$\quad$ Present & 1 & 0 \\
\hline
\end{tabular}

intercurrent mood disorder, whereas no intercurrent mood disorders were detected in the control group. Although there was no significant difference in the total number of recent life events experienced by each group, $14(70 \%)$ of the patients with BA had experienced one or more life events relating to their asthma in the six months before interview, compared with two of the control group $(\mathrm{p}<0.001)$.

\section{Discussion}

While early work, such as the study by Rees, ${ }^{1}$ identified the importance of psychological factors in the pathogenesis of asthma, the findings of such studies are difficult to interpret because standardised instruments or diagnostic criteria were not in common use at that time. Although a later study ${ }^{2}$ did not find a difference in incidence of mental illness or level of social function between groups of asthmatic patients and a control population, the index cases had very mild asthma, the majority having been symptom free for at least three years before follow up. An Australian study ${ }^{11}$ of patients who had suffered life threatening episodes of asthma failed to find any difference in psychiatric morbidity when compared with a control group of asthmatic patients. It did find higher than expected levels of psychiatric morbidity, however, and, in particular, a preponderance of anxiety disorders in both groups, compared with subjects without asthma.

Recently, studies of psychological factors in asthma have examined the role of life events. The onset of asthma has been reported to follow life events such as a bereavement, ${ }^{12}$ but there is no evidence that any particular event is more common, ${ }^{1}$ or that people with established asthma experience more independent events. ${ }^{1314}$ Adversity may be of relevance, however; although no significant difference in level of social function was found between asthmatic patients and a control group in one study, ${ }^{2}$ others ${ }^{15}$ have found a correlation between life problems-that is, work and family relationships - and severity of asthma as measured by subjective reports. This correlation disappeared, however, when severity was measured by physicians' ratings or PEF. ${ }^{15}$ Another study has found that severity of asthma correlated with hospitalisation and asthma dependent life change, but not with independent events. ${ }^{13}$ Although these findings are of interest, it is difficult to compare them with other studies of life events, adversity, and social difficulty, because of the wide variation in measures used.

Claims for a specific predisposing personality in asthma have failed to be substantiated by other studies using various personality rating scales, ${ }^{1617}$ and the results of our study are comparable to the published normal data. ${ }^{18}$ Although certain personality traits such as anxiety, timidity, sensitivity, and obsessionality were found by Rees, ${ }^{1}$ it has been suggested that such findings might simply reflect the effects of prolonged chronic illness. ${ }^{2}$ 
Increased denial in a group of asthmatic patients with a "near miss death experience" has, however, been reported, ${ }^{18}$ and other workers have found that measures of personality and self esteem correlated significantly with patients' symptoms but not with more objective measures of severity, such as use of oral steroids and levels of PEF. ${ }^{15}$

A failure to find any difference in psychiatric or social morbidity might reflect the tendency of most studies to examine heterogenous groups of asthmatic patients. With the exception of the studies of asthmatic subjects with near death experiences ${ }^{11}{ }^{19}$ and a study from America, ${ }^{15}$ no work appears to be directed at those patients with severe asthma, who have the highest morbidity and mortality, and require a great deal of specialist attention. By the use of well recognised instruments to detect psychiatric disorder, this study therefore specifically examined such a group of patients with BA, a group in which clinical impression suggested increased psychosocial morbidity.

Although there was no significant difference between the two groups in terms of the numbers of patients scoring above the threshold of 11 on the GHQ, our purpose in using the GHQ was to discover whether it might be a useful screening agent for psychiatric disorder in the chest clinic. The GHQ was designed specifically for use in primary care and medical outpatients, ${ }^{6}$ and is the most widely used and best validated of the screening tests available. It has been used in other studies of asthmatic subjects ${ }^{20}$ so results can readily be compared with those in our study. The finding that the GHQ detected $80 \%$ of patients with intercurrent psychiatric disorder suggests that it may be a relatively sensitive indicator. In this study, however, we found it to be less specific, since five control cases scored above the threshold, but only two of these control subjects were found to have intercurrent psychiatric disorder with the SCID. If the threshold is increased, as suggested by Goldberg, ${ }^{8}$ the specificity in this study declines. Furthermore, although the prevalence of psychiatric disorder in the control group in this study appears high, studies with the GHQ in other medical outpatient settings also find surprisingly high levels of psychiatric morbidity-for example, $18 \%$ in insulin dependent diabetics, ${ }^{21}$ and $48 \%$ in neurology outpatients. ${ }^{22}$ More extensive study of the use of the GHQ in this area might be warranted.

The increased psychiatric morbidity found in the patients with BA contrasts with the results of Benjamin's study, ${ }^{2}$ but is comparable, both in terms of overall psychiatric morbidity and the prevalence of anxiety disorders, to the "near miss asthma death" group. ${ }^{19}$ This excess of psychiatric morbidity raises the question of how psychiatric disorder and asthma interact. BA might in some way predispose to psychiatric disorder, or psychiatric disorder might increase the risk of developing BA. It has been suggested that following "near miss asthma death" experiences, patients appear to either decompensate psychiatrically, usually exhibiting symptoms of anxiety disorders, or to increase their levels of denial. ${ }^{19}$ We failed to find increased levels of denial as measured by the lie scale of the EPI, one of the instruments used in the former study. ${ }^{19}$ Furthermore, there is no direct evidence from this study to suggest that having BA predisposes to psychiatric illness, but it is possible that medication such as subcutaneous $\beta_{2}$ agonists and oral steroid preparations may play a part. Even if one postulates that psychiatric disorder may be of relevance to $\mathrm{BA}$, however, the majority of the patients with $\mathrm{BA}$ in this study did not have any psychiatric abnormality. Mental disorder might be considered to affect a patients' ability to cope with having chronic asthma as well as affecting treatment compliance. There is evidence to suggest that people with high levels of anxiety which are not exclusively related to exacerbations of asthma ${ }^{23}$ have higher rates of hospitalisation, and greater use of "as required" medication and oral steroids. ${ }^{24}$ Conversely, symptoms of anxiety which only occur during asthmatic attacks (panic/fear), have been suggested as leading to more appropriate action by the patient. ${ }^{24} 25$ Although the high prevalence of anxiety disorders in patients with BA suggests that anxiety management might be a useful adjunct to medical treatment, the type of anxiety experienced by the patient is therefore important. Anxiety focused on breathing difficulties might be adaptive, whereas chronic anxiety concomitant with a lack of basic ego resources probably interferes with effective self management. ${ }^{2425}$

Ostensibly there was good compliance in both of our groups, as was the case in patients who had experienced a life threatening episode of asthma. ${ }^{11}$ This factor needs to be borne in mind, however, especially in the light of findings of poor compliance among other groups such as "brittle diabetics", ${ }^{26}$ and the association of non-compliance and risk of dying from asthma. ${ }^{3}$

Sibbald and colleagues have shown that patients with the highest morbidity from asthma have greater feelings of stigma, less positive attitudes to their doctor, and less self confidence in managing asthma attacks. ${ }^{27}$ In a later study ${ }^{20}$ she showed that patients with the highest morbidity from asthma delay longest before using bronchodilators or summoning medical help in a hypothetical acute attack. She did not find a significant association between self care and psychiatric morbidity, family support, duration of asthma, or patient's knowledge. The levels of psychiatric morbidity as measured by the GHQ (38\%) were, however, surprisingly high considering that the source of many of the patients was general practice. She suggested that chronic severe asthma may foster indifference to acute asthma leading the patient to delay in taking appropriate action. She advocated health education designed to change undesirable behaviour, and suggested that the hypothetical attack scenarios which had identified 
self care problems might be more helpful in teaching patients appropriate strategies than simply increasing "knowledge" which does not appear to be correlated with improved asthma morbidity. ${ }^{28} 29$

Sibbald emphasised that there is a need for more information about the ways in which psychosocial factors interact with asthma morbidity, in particular the way in which morbidity may shape attitudes, and attitudes shape morbidity. ${ }^{20}$ Her findings are clearly relevant to future investigation of patients with BA, since better understanding of these interactions might lead to development of appropriate psychological intervention as an adjunct to medical treatment. We would suggest that our findings are also of relevance to the practising clinician, since identification of psychiatric morbidity or deficient coping skills in patients with poorly controlled asthma might indicate a need to consider them as part of the overall management.

We would like to thank Dr P S Burge, Dr R M Cayton, and Dr D E Stableforth for allowing us to include their patients in the study; Miss Andrea Thomas for performing the statistical analyses, and Dr Femi Oyebode and Dr David Boldy for their constructive comments and criticisms.

1 Rees L. Physical and emotional factors in bronchial asthma. F Psychosom Res 1956;1:98-114.

2 Benjamin S. Is asthma a psychosomatic illness?-I. A retrospective study of mental illness and social adjustment. $\mathcal{F}$ Psychosom Res 1977;21:463-9.

3 Rea HH, Scragg R, Jackson R, Beaglehole R, Fenwick J, Sutherland DC. A case-control study of deaths from asthma. Thorax 1986;41:833-9.

4 Turner-Warwick M. On observing patterns of airflow obstruction in chronic asthma. Br $\mathcal{f}$ Dis Chest 1977; 71:73-86.

5 O'Driscoll BRC, Ruffles SP, Ayres JG, Cochrane GM. Long term treatment of severe asthma with subcutaneous terbutaline. Br $\mathcal{F}$ Dis Chest 1988;82:360-7.

6 Goldberg DB. The detection of psychiatric illness by questionnaire. Maudsley Monograph No. 21, Oxford: Oxford University Press, 1972

7 Eysenck HJ, Eysenck SBG. Manual of the Eysenck personality inventory. Sevenoaks: Hodder and Stoughton, 1964.

8 Goldberg D. Use of the General Health Questionnaire in clinical work. BMF 1986;293:1188-9.

9 Spitzer RL, Williams JBW, Gibbon M. Instruction manual for the structured clinical interview for DSM-III-R SCID. New York: Biometrics Research Department, New York
State Psychiatric Institute, 1987.

10 Paykel ES. Methodological aspects of life events research f Psychosom Res 1983;27:341-52.

11 Yellowlees PM, Haynes S, Potts N, Ruffin RE. Psychiatric morbidity in patients with life-threatening asthma: initial report of a controlled study. Med $\mathcal{f}$ Aust 1988;149:246-9.

12 Levitan $H$. Onset of asthma during intense mourning. Psychosomatics 1985;26:939-41.

13 Northup L, Weiner MF. Hospitalization, life change and ability to cope with asthma. F Psychosom Res 1984; 28:177-83.

14 Steinhausen H-C. Life events in relation to psychopathology among severely and chronically ill children and adolescents. Child Psychiatry Hum Dev 1983;13:249-58.

15 Plutchik R, Williams H Jr, Jerrett I, Karasu TB, Kane C. Emotions, personality and life stresses in asthma. $f$ Psychosom Res 1978;22:425-31.

16 Spittle BJ, Sears MR. Bronchial asthma: lack of relationships between allergic factors, illness severity and psychosocial variables in adult patients attending an asthma clinic. Psychol Med 1984;14:847-52.

17 Teiramaa E. Psychosocial factors, personality and acute insidious asthma. F Psychosom Res 1981;25:43-9.

18 Saville $\mathrm{P}$, Blinkhorn S. British undergraduate norms to the LAS, NSQ and EPI. Windsor: NFER-NELSON, 1981:23.

19 Yellowlees PM, Ruffin RE. Psychological defenses and coping styles in patients following a life-threatening attack of asthma. Chest 1989;95:1298-303.

20 Sibbald B. Patient self care in acute asthma. Thorax 1989;44:97-101.

21 Wilkinson G, Borsey DQ, Leslie P, Newton RW, Lind C, Ballinger CB. Psychiatric morbidity and social problems in patients with insulin-dependent diabetes mellitus. $B r$ f Psychiatry 1988;153:38-43.

22 Kirk CA, Saunders M. Psychiatric illness in a neurological outpatient department in north east England. Acta Psychiatr Scand 1979;60:427-37.

23 Dirks JF, Jones NF, Kinsman RA. Panic-fear: a personality dimension related to intractability in asthma. Psychosom Med 1977;39:120-6.

24 Dirks JR, Kinsman RA, Staudenmayer H, Kleiger JH Panic-fear in asthma. Symptomatology as an index of signal anxiety and personality as an index of ego resources. I Nerv Ment Dis 1979;167:615-9.

25 Staudenmayer H, Kinsman RA, Dirks JF, Spector SL, Wangaard C. Medical outcome in asthmatic patients: effects of airways hyperreactivity and symptom-focused anxiety. Psychosom Med 1979;41:109-18.

26 Tattersall $R$, Walford $S$. Brittle diabetes in response to life-stress: "cheating and manipulation". In: Pickup JC, ed. Brittle diabetes. Oxford: Blackwell, 1985:76-101.

27 Sibbald B, White P, Pharoah C, Freeling P, Anderson HR. Relationship between psychosocial factors and asthma morbidity. Fam Pract 1988;5:12-17.

28 Hilton S, Sibbald B, Anderson HR, Freeling P. Evaluating health education in asthma-developing the methodology: preliminary communication. $f R$ Soc Med 1982; 75:625-30.

29 Hilton S, Sibbald B, Anderson HR, Freeling P. Controlled evaluation of the effects of patient education on asthma morbidity in general practice. Lancet 1986; i:26-9. 